\title{
Multi-scale modelling of OSN batch concentration with spiral-wound membrane modules using OSN Designer
}

Binchu Shi ${ }^{a}$, ${ }^{b}$ Dimitar Peshev ${ }^{c}$, Patrizia Marchetti ${ }^{b}$, Shengfu Zhang ${ }^{a}$, Andrew G. Livingston ${ }^{a}, b, *$

a Evonik Membrane Extraction Technology Limited, Unit 6 Greenford Park, Ockham Drive, Greenford, London, UB6 OAZ, United Kingdom

${ }^{b}$ Department of Chemical Engineering, Imperial College London, Exhibition Road, London SW7 2AZ, United Kingdom

c Department of Chemical Engineering, University of Chemical Technology and Metallurgy, 8, Kl. Ohridsky Blvd, Sofia 1756, Bulgaria

* Corresponding author. Addr.: Department of Chemical Engineering, Imperial College London, Exhibition Road, London SW7 2AZ, United Kingdom; Tel.: +44-20-7594-5582. E-mail address: a.livingston@imperial.ac.uk

\begin{abstract}
Three commercial spiral-wound membrane modules of different sizes, from $1.8 " x 12$ " to $4.0 " x 40 "$, are used to concentrate a solution of sucrose octaacetate in ethyl acetate under different operating conditions. A mathematical model to describe the batch concentration process is developed, based on a combination of the classical solution diffusion membrane transport model and the film theory, to account for the mass transfer effects. The model was implemented using the "OSN Designer" software tool. The membrane transport model parameters as well as all parameters in the pressure drop and mass transfer correlations for the spiral-wound modules were obtained from regression on a limited number of experimental data at steady state conditions. Excellent agreement was found between the experimental and multi-scale modelling performance data under various operating conditions. The results illustrate that the performance of a large scale batch concentration process with spiral-wound membrane modules can be predicted based on laboratory crossflow flat sheet test data when the fluid dynamics and mass transfer characteristics in the module, and the necessary channel geometry are known. In addition, the effects of concentration polarisation, pressure drop through feed and permeate channels, and thermodynamic non-ideality of the solution at large scale batch concentration are also investigated.
\end{abstract}


Keywords: batch concentration, spiral-wound membrane module, organic solvent nanofiltration, multi-scale modelling, OSN Designer

\section{Introduction}

Primarily, research activities in the field of organic solvent nanofiltration (OSN) have been focused on the development of new materials stable in organic solvents and harsh conditions, while industrial scale applications are still few. A fundamental understanding of the basic separation mechanism and a reliable modelling framework are crucial to bridge this gap, meet the growing needs and applications, and make the scale-up more efficient and economic [White, 2006]. In the development of a multi-scale mathematical model for an OSN process with spiral-wound membrane modules, the following problems have to be resolved: (i) selection of adequate membrane transport mechanism to describe the molecular transport across the membrane; (ii) knowledge of the fluid dynamics and mass transfer characteristics in the module; (iii) availability of the thermodynamic and physical properties of the solutions under different operating conditions.

Marchetti and Livingston [Marchetti and Livingston, 2015] systematically compared different models (based on irreversible thermodynamics, pore-flow, solution-diffusion and hybrid approaches) using selected experimental data and concluded that the classical solution-diffusion model gives the best description of permeation through flexible chain glassy membranes and rubbery membranes, without overcomplicating (or overparameterising) the modelling procedure. Since the thin film composite membrane used in this study has a rubbery separating layer, the classical solution diffusion model was selected to describe the membrane transport.

Many studies [Schock and Miquel, 1987; Schwinge et al., 2000; Li et al., 2002; Fimbres-Weihs and Wiley, 2007; Koutsou et al. 2009] have been published on the fluid dynamics and mass transfer characteristics in spacer-filled channels, which mimic the channel of spiral-wound membrane modules, in aqueous solutions. Various dimensionless correlations for the friction coefficient and the Sherwood number were generated. However, from the point of view of process design, there is still lack of suitable correlations for OSN applications, due to the fact that the correlations derived from aqueous solutions may not be suitable for OSN applications where the Reynolds and 
Schmidt numbers can vary more significantly. Furthermore, the fluid dynamics and mass transfer characteristics are dependent on the spacer geometry which is usually confidential in commercial modules, and unknown for end users. Recently, Shi et al. [Shi et al., 2015] proposed a procedure to generate correlations for characterising the fluid dynamics and mass transfer characteristics in spiral-wound membrane modules. Specifically, three correlations for describing the friction coefficients in both the feed and permeate channels and the Sherwood number in the feed channel for OSN applications were proposed.

The last stage in the development of a multi-scale process model is the availability of all required thermodynamic and physical properties of the solutions of interest, as a function of the operating conditions. Considering that the collection of thermodynamic and physical data for all the possible solute/solvent combinations by experiments would be prohibitively time consuming, it is useful to rely on a simulation tool to predict the values of these properties. Peshev and Livingston [Peshev and Livingston, 2013] recently proposed a tool, "OSN Designer", which makes OSN unit operations available in process modelling environments such as Aspen Plus, HYSYS and ProSim Plus, to streamline OSN process design. The thermodynamic and physical properties of the solutions were obtained from the Aspen Properties Database or estimated using built-in models in the process modelling environment. This tool was validated using published experimental data under steadystate and batch conditions.

Some examples for application of OSN to concentration and purification in industrial applications have been published previously. For instance, OSN was applied to the recovery and purification of pharmaceuticals [Cao et al., 2001; Marchetti et al., 2013; Sun et al., 2014], solvent exchange [Sheth et al., 2003], separation of base chemicals [Werhan et al., 2012; Othman et al., 2010], purification and concentration of consumer chemicals [Vanneste et al., 2011; Tsibranska and Tylkowski, 2013], concentration and purification of specialty chemicals [Tsui and Cheryan, 2007], and homogeneous catalyst recycle [Van der Gryp et al., 2010]. These studies showed the feasibility of OSN technologies in different industries at laboratory scale with flat sheet membranes or with 1.8"x12" spiral-wound membrane modules. In the literature, only a few studies [Peshev et al., 2011; Vanneste et al., 2013; Sereewatthanawut et al., 2010] proposed mathematical models for prediction of the process performance. In these process models, the mass balance equations were 
derived based on the assumptions of well-mixed solutions in a feed tank and negligible time consumed for retentate circulation. Under these assumptions, the process models showed good agreement with the experimental data. However, the process models were not capable of predicting the performance of other applications. This was due to the fact that they used empirical, non-predictive membrane transport models, which assume constant flux and rejection over time. This has been shown to be unrealistic in many cases [Shi et al., 2015; Peeva et al., 2004].

The objective of this work is to show how simulation can be successfully used to describe an OSN process in several configurations. Three commercial spiral-wound membrane modules of different sizes, from 1.8 "x12" to $4.0 " x 40 "$, are used to concentrate a solution of sucrose octaacetate in ethyl acetate under various pressures and retentate flowrates. A mathematical model to describe the batch concentration process is developed, based on combination of the classical solution diffusion membrane transport model and the film theory, to account for the mass transfer effects. The model was implemented via the "OSN Designer" software tool [Peshev and Livingston, 2013]. The membrane transport model parameters as well as all parameters in the pressure drop and mass transfer correlations for the spiral-wound modules were obtained from regression on a limited number of experimental data obtained at steady state conditions [Shi et al., 2015] and used to simulate the performance of a batch concentration process. This study discusses the potential of this approach to predict the performance of any OSN process which uses spiral-wound membrane modules, based on simple flat sheet test data. In addition, the effects of concentration polarisation, pressure drops through feed and permeate channels and thermodynamic nonideality of the solution at large scale batch concentration are also investigated.

\section{Materials and Methods}

\subsection{Materials}

Analytical grade ethyl acetate was purchased from Tennants Distribution Limited, UK. Sucrose octaacetate ( $>97 \%$ purity) was purchased from Sigma Aldrich Limited, UK. The high solubility of sucrose octaacetate in ethyl acetate makes this binary system appropriate for the present study, since it allows relatively high concentration to be achieved. 
Three spiral-wound PuraMem ${ }^{\circledR}$ S600 membrane modules were provided by Evonik Membrane Extraction Technology Limited, covering three sizes: 1.8"x12", 2.5"x40" and 4.0"x40". According to the supplier, the feed and permeate spacers in these modules are EMET-F3 and EMET-P1, respectively and both the length and width of the permeate channel are about $70 \mathrm{~mm}$ shorter than the feed channel due to the presence of glue lines on the permeate side. Details of these three modules are summarised in Table 1.

Table 1 Configuration of the three spiral-wound PuraMem ${ }^{\circledR} \mathrm{S} 600$ membrane modules used in this study. All information is provided by the supplier.

\begin{tabular}{ccccc}
\hline $\begin{array}{c}\text { Module } \\
\text { code }\end{array}$ & $\begin{array}{c}\text { Module } \\
\text { Size }\end{array}$ & $\begin{array}{c}\text { Membrane } \\
\text { Area }\left(\mathbf{m}^{2}\right)\end{array}$ & $\begin{array}{c}\text { Number of } \\
\text { Leaves }\end{array}$ & $\begin{array}{c}\text { Module Body } \\
\text { Length }(\mathbf{m m})\end{array}$ \\
\hline SWMM-1 & $1.8^{\prime \prime} \times 12^{\prime \prime}$ & 0.14 & 1 & 175 \\
SWMM-2 & $2.5^{\prime \prime} \times 40 "$ & 1.74 & 2 & 886 \\
SWMM-3 & $4.0^{\prime \prime} \times 40 "$ & 5.19 & 4 & 886 \\
\hline
\end{tabular}

\subsection{Experimental methods}

In this work, the three commercial modules were operated in batch concentration mode using three different experimental rigs. The SWMM-1 and SWMM-2 modules were incorporated in a single-pump system, which is schematically represented in Figure 1 as the solid and dashed route. The SWMM-1 module was operated using a single diaphragm pump (Hydra-Cell D3) and the retentate flowrate was controlled between 80 and $240 \mathrm{~L} \mathrm{~h}^{-1}$. The SWMM-2 module was operated using a more powerful diaphragm pump, capable of controlling the flowrate from 300 to $900 \mathrm{Lh}^{-1}$ (Hydra-Cell D10). The SWMM-3 module was incorporated in a two-pump rig shown as the solid and dotted route in Figure 1. Compared to the one-pump rig, a circulation pump (Peripheral-Pump $\mathrm{HMH} 125$ ) was added in this rig, to provide sufficient cross-flow velocity through the feed channel of the module. After Flow Indicator 2, a fraction of the retentate circulates through the module with a high flowrate, forming an inner circulation loop (Heat Exchanger $2 \rightarrow$ Circulation Pump $\rightarrow$ 4.0"x40" Module Housing $\rightarrow$ Pressure Indicator $4 \rightarrow$ Flow Indicator $2 \rightarrow$ Heat Exchanger 2). The remaining fraction of the retentate flows back to the feed tank (recycle fraction). The retentate 
flowrate through the module in the inner circulation loop was controlled between 1000 and 3000 $L h^{-1}$.

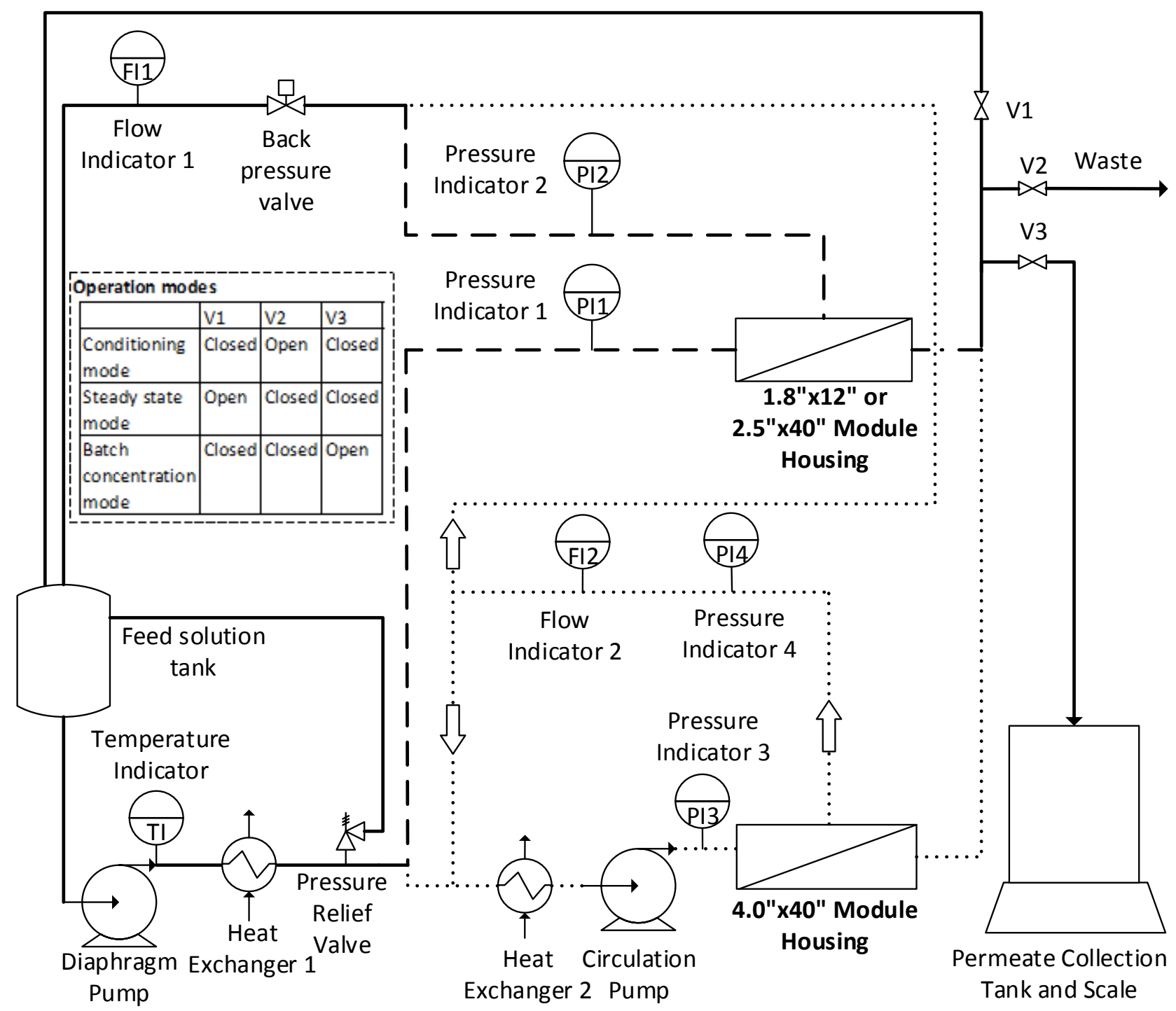

Figure 1. Schematic representation of the experimental set-up for the batch concentration process using spiral-wound membrane modules. Solid and dashed route: the single-pump configuration for both SWMM-1 and SWMM-2 modules; Solid and dotted route: the two-pump configuration for the SWMM-3 module.

A summary of the operating conditions of the batch concentration operation with the three different modules is reported in Table 2. In the SWMM-3 module test, the flowrate of the recirculating solution (read from Flow Indicator 1, shown in Figure 1) was controlled to be about 
$85 \pm 11 \mathrm{~L} \mathrm{~h}^{-1}$. All modules were washed using pure ethyl acetate (Valves 1 and 3 closed; Valve 2 open) and tested in the initial solution for 6 hours at steady state conditions (Valve 1 open; Valves 2 and 3 closed) before switching to the batch concentration mode (Valves 1 and 2 closed; Valve 3 open).

Table 2. Operating conditions of the batch concentration with different spiral-wound membrane modules.

\begin{tabular}{|c|c|c|c|c|c|c|c|}
\hline Entry & Module & $\begin{array}{c}\text { Initial feed } \\
\text { volume } \\
\text { (L) }\end{array}$ & $\begin{array}{c}\text { Initial feed } \\
\text { concentration } \\
\text { (wt \%) }\end{array}$ & $\begin{array}{c}\text { Temperature } \\
\left({ }^{\circ} \mathrm{C}\right)\end{array}$ & $\begin{array}{c}\text { Pressure } \\
\text { (bar) }\end{array}$ & $\begin{array}{c}\text { Retentate } \\
\text { flowrate } \\
\left(L h^{-1}\right)\end{array}$ & $\begin{array}{c}\text { Process } \\
\text { time } \\
\text { (min) }\end{array}$ \\
\hline 1 & $1.8^{\prime \prime x 12 " ~}$ & 6 & 3.9 & 30 & 10 & 80 & 110 \\
\hline 2 & $1.8^{\prime \prime} \times 12^{\prime \prime}$ & 6 & 3.9 & 30 & 10 & 240 & 110 \\
\hline 3 & 1.8"x12" & 6 & 3.9 & 30 & 30 & 80 & 40 \\
\hline 4 & $1.8^{\prime \prime} \times 12^{\prime \prime}$ & 6 & 3.9 & 30 & 30 & 240 & 40 \\
\hline 5 & $2.5 " x 40 "$ & 80 & 2.5 & 30 & 10 & 300 & 150 \\
\hline 6 & $2.5^{\prime \prime} \times 40 "$ & 80 & 2.5 & 30 & 10 & 900 & 150 \\
\hline 7 & $2.5^{\prime \prime} \times 40 "$ & 80 & 2.5 & 30 & 30 & 300 & 50 \\
\hline 8 & $2.5^{\prime \prime} \times 40 "$ & 80 & 2.5 & 30 & 30 & 900 & 50 \\
\hline 9 & $4.0 " \times 40 "$ & 80 & 6 & 30 & 10 & 1000 & 70 \\
\hline 10 & 4.0"x40" & 80 & 6 & 30 & 10 & 3000 & 70 \\
\hline 11 & $4.0 " x 40 "$ & 80 & 6 & 30 & 30 & 1000 & 20 \\
\hline 12 & 4.0"x40" & 80 & 6 & 30 & 30 & 3000 & 20 \\
\hline
\end{tabular}

The performance of the membrane batch concentration operations was characterised by three parameters: the change of the volume of the feed solution, the change of the solute concentration in the tank and the percentage loss of the solute to permeate, all over time. The volume of the feed solution at each time $t, V_{F, t}$, is calculated as the difference between the volume of the initial feed solution, $V_{F, 0}$, and the cumulative permeate volume, $V_{P, t}$. This is shown in Equation (1). The permeate was collected in a separate container and the weight was measured over time using a 
scale with a capacity of $20 \mathrm{~kg}$ for the SWMM-1 module and $200 \mathrm{~kg}$ for both the SWMM-2 and SWMM-3 modules. The accuracy is $\pm 0.1 \mathrm{~g}$ for the SWMM-1 module and $\pm 10 \mathrm{~g}$ for both the SWMM-2 and SWMM-3 modules. The volume of permeate was then calculated using the density of the solution which was obtained from concentration analysis of a permeate sample taken from the permeation collection tank at the same time point. The feed samples were also taken at discrete times for analysing the solute concentration in the tank, and its change over time. The percentage loss of solute to permeate at time $t, L_{S, t}$, in the feed tank was calculated using Equation (2). $C_{F, S, 0}$ is the initial solute concentration in the feed and $C_{P, S, t}$ is the solute concentration in the permeate at process time $t$.

$V_{F, t}=V_{F, 0}-V_{P, t}$

Equation (1)

$L_{S, t}=\frac{V_{P, t} \cdot C_{P, S, t}}{V_{F, 0} \cdot C_{F, S, 0}}$

Equation (2)

The concentration of sucrose octaacetate was determined using a gas chromatograph with a flame ionisation detector and a fused silica column ( $\mathrm{Rtx}^{\circledR}-2887$ column purchased from Thames Restek Limited, UK) [Shi et al., 2015]. The temperature programme ran from 40 to $300{ }^{\circ} \mathrm{C}$ at a rate of 15 ${ }^{\circ} \mathrm{C} \mathrm{min}^{-1}$, and then remained at $300{ }^{\circ} \mathrm{C}$ for $10 \mathrm{~min}$. The flowrate of the carrier gas (helium) was set at $0.7 \mathrm{ml} \mathrm{min}^{-1}$.

\subsection{Modelling}

The modelling in this work was carried out using the OSN Designer software tool where all thermodynamic and physical properties of the solutions were obtained using the Aspen Properties Estimate system with the Dortmund modified UNIFAC (UNIF-DMD) as a base method in the Aspen Plus V7.3 environment [Shi et al., 2015]. A mathematical model for the batch concentration operation considering the gradients of concentration, pressure and velocity through the module, the concentration polarisation and the thermodynamic non-ideality of the solutions was programmed in MATLAB, which communicates with Aspen Plus via the CAPE OPEN interface, as shown in Figure 2. 


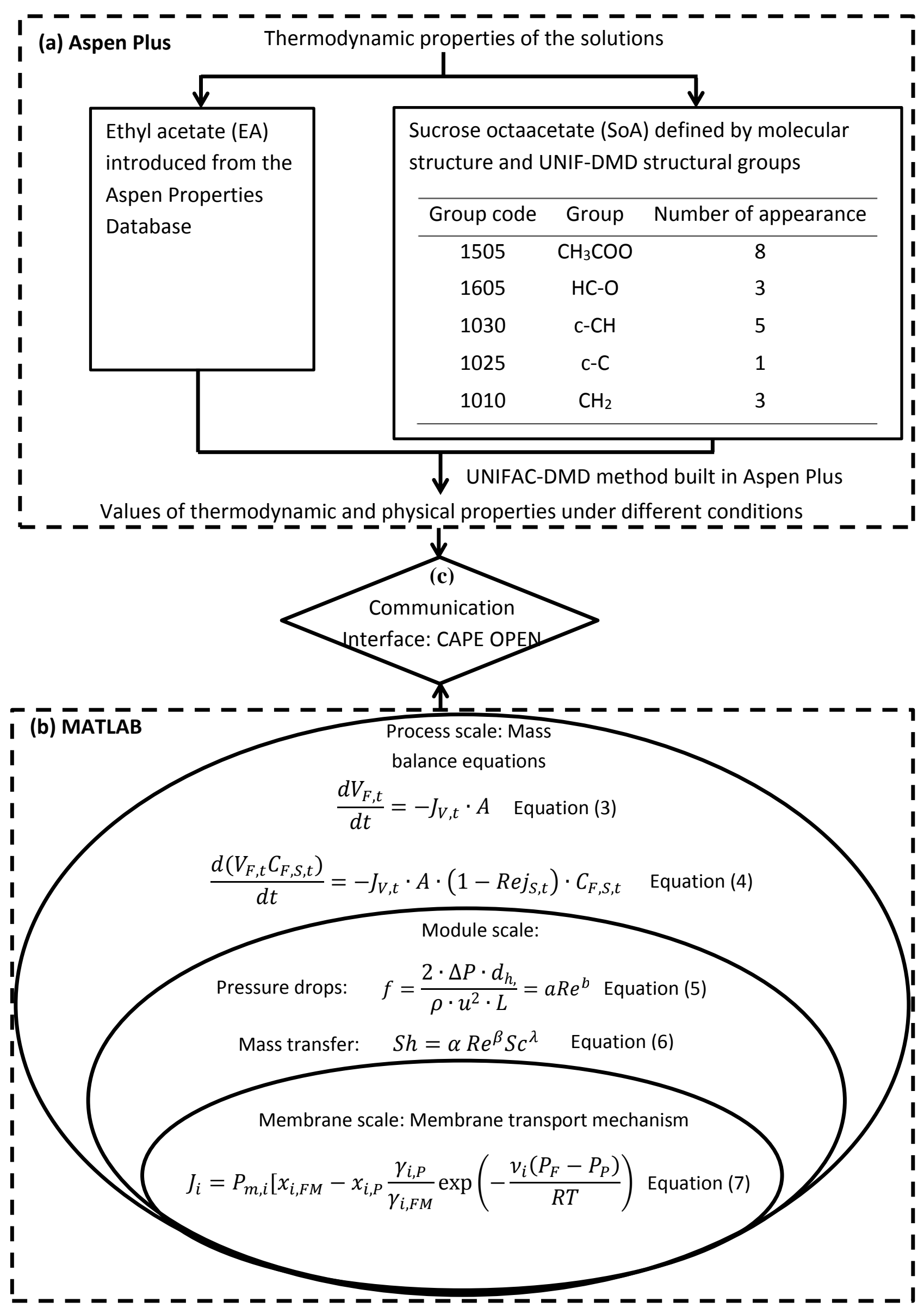


Figure 2: Schematic representation of the OSN Designer software used to simulate the batch concentration operations in this work. (a) Calculation of the thermodynamic properties of the solutions using UNIFAC-DMD model in Aspen Plus; (b) multi-scale modelling of the batch concentration unit operation at membrane, module and process scales in MATLAB; (c) CAPE OPEN interface for communication between Aspen Plus and MATLAB.

As shown in Figure 2(a), ethyl acetate was available from the database in Aspen Plus while sucrose octaacetate is defined using UNIFAC-DMD structural groups since it is not available in the Aspen Properties Database [Shi et al., 2015]. The material balance equations for the entire batch concentration operation are represented by Equations (3) and (4) (see Figure 2(b)). $A$ is the effective membrane area in the module. $J_{V, t}$ and $R e j_{S, t}$ are the permeate flux and rejection at process time $t$, respectively. It is assumed that the solution in the feed tank is well mixed and the time consumed for the retentate circulation is negligible. The flux and rejection through the module are calculated using the combination of the solution-diffusion model and the film theory, as presented in Equation (7) (see Figure 2(b)). $P_{m, i}$ is the permeability coefficient for the species $\mathrm{i}$ ( $i=1$, solute; $i=2$, solvent). $\mathrm{J}$ is the molar flux, $\mathrm{x}$ is the molar fraction, $\gamma$ is the activity coefficient, $v$ is the molar volume, $\mathrm{P}$ is the pressure, $\mathrm{R}$ is the ideal gas constant and $\mathrm{T}$ is the temperature. The subscripts P, F and FM refer to the permeate side, the feed side and the feed side membraneliquid interface, respectively. The pressure drops through both the feed and permeate channels and the mass transfer effects were considered by using the friction coefficient and Sherwood number correlations, shown as Equations (5) - (6) (see Figure 2(b)). $f$ is the friction coefficient and $\Delta P$ is the pressure drop through the channel. $d_{h}$ is the hydraulic diameter of the channel, $L$ is the length of the channel, $\rho$ is the density of the solution, $u$ is the velocity of the flow along the channel, $\mu$ is the dynamic viscosity of the solution. $R e, S c$ and $S h$ are the dimensionless Reynolds, Schmidt and Sherwood numbers. $a$ and $\alpha$ are coefficients in the correlations, and $b, \beta$ and $\lambda$ are exponents in the correlations. In this work, all parameters and correlations were taken from Shi et al. [Shi et al., 2015] since the membrane modules are made of the same membranes and spacers and tested in solutions containing the same components. The membrane transport properties, feed and permeate channel geometry, fluid dynamics and mass transfer characteristics are summarised in Table 3. Besides, the permeate flux, $J_{V, t}$ and the solute rejection, $R e j_{S, t}$, are defined as Equations (8) and (9), respectively. 
$J_{V, t}=\frac{F_{P, t}}{A}$

Equation (8)

$\operatorname{Rej}_{S, t}=\left(1-\frac{C_{P, S, t}}{C_{R, S, t}}\right) \cdot 100 \%$

Equation (9)

$F_{P, t}$ is the permeate flowrate at process time $t$ and $C_{R, S, t}$ is the concentration of the solute in the retentate at process time $t$.

Table 3 Summary of the model parameters required to simulate the batch concentration processes (from Shi et al. [Shi et al., 2015]): membrane transport properties, feed and permeate channel geometry, fluid dynamics and mass transfer characteristics.

\begin{tabular}{|c|c|c|}
\hline \multirow{2}{*}{ Membrane } & Solute permeability coefficient $\left(\mathrm{mol} \mathrm{m}^{-2} \mathrm{~s}^{-1}\right)$ & $2.06 \mathrm{E}-3$ \\
\hline & Solvent permeability coefficient $\left(\mathrm{mol} \mathrm{m}^{-2} \mathrm{~s}^{-1}\right)$ & 1.59 \\
\hline \multirow{5}{*}{ Feed channel } & Height (mm) & 0.77 \\
\hline & Void fraction (-) & 0.827 \\
\hline & Hydraulic diameter $(\mathrm{mm})$ & 0.79 \\
\hline & Friction coefficient correlation & $f_{F}=6.94 R e_{F}^{-0.34}$ \\
\hline & Sherwood number correlation & $S h_{F}=0.075 R e_{F}^{0.61} S c_{F}^{0.33}$ \\
\hline \multirow{4}{*}{$\begin{array}{l}\text { Permeate } \\
\text { channel }\end{array}$} & Height $(\mathrm{mm})$ & 0.27 \\
\hline & Void fraction (-) & 0.315 \\
\hline & Hydraulic diameter (mm) & 0.048 \\
\hline & Friction coefficient correlation & $f_{P}=16 R e_{P}^{-0.34}$ \\
\hline
\end{tabular}

In addition, in the development of a new OSN process, the first step is usually to screen the membranes in cross-flow cells and then to prove that the chosen membrane performs well in a small 1.8"x12" module before scale-up. Therefore, even for a different application using different modules, the experimental data (both flat sheets and a 1.8"x12" module) are usually available a priori, to obtain the model parameters using the procedure developed in the study [Shi et al., 2015]. 


\section{Results and discussion}

Figures $3-5$ show the performance of the batch concentration operations with different commercial spiral-wound membrane modules of different sizes (1.8"x12", 2.5"x40" and 4.0"x40", respectively) under various retentate flowrates and feed pressures with sucrose octaacetate / ethyl acetate solutions. The feed solutions were concentrated three to four times from relatively low concentration (2.5 - $6 \mathrm{wt} \%)$ to high concentration (12-21 wt\%). For all three modules, it can be seen that the volume in the feed tank decreases and the solute concentration in the feed tank increases over time. Furthermore, increasing the feed pressure can accelerate the batch concentration process due to the increase in the permeate flux: in Figures 3-5(a,b), obtained at 10 bar, the process is completed in 110, 150 and 70 minutes for SWMM-1, SWMM-2 and SWMM-3, respectively, while in Figures $3-5(c, d)$, obtained at 30 bar, the process time is completed in 40,50 and 22 minutes, respectively. The retentate flowrate has also a positive effect on the concentration process: in Figures 3-5(a,c), obtained at low retentate flowrate, the process time is 2 - 7 minutes longer than at high retentate flowrate in Figures 3-5(b,d). This occurs because high retentate flowrate reduces the concentration polarisation, increases the permeation flux and thus makes the concentration process faster. 
(a) $10 \mathrm{bar}, 80 \mathrm{~L} \mathrm{~h}^{-1}$

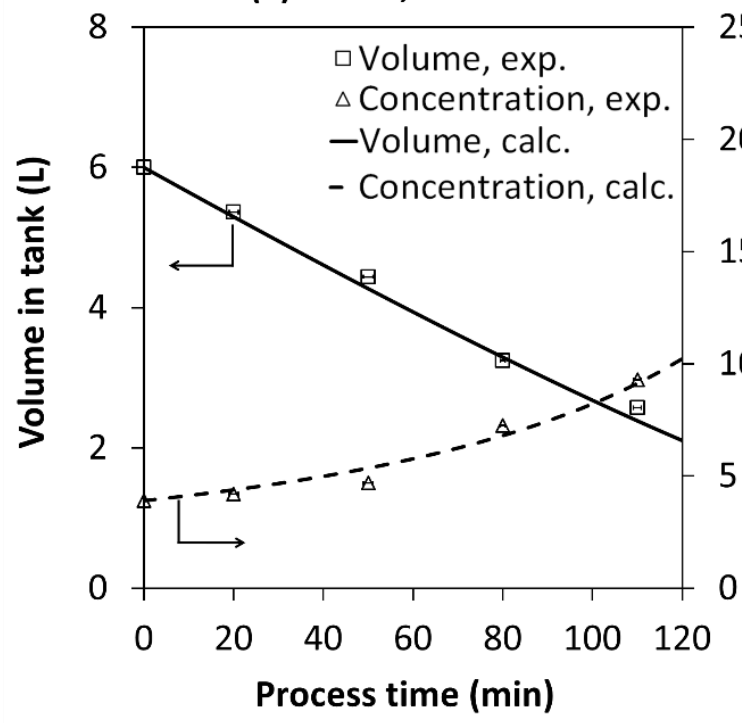

(c) 30 bar, $80 \mathrm{Lh}^{-1}$

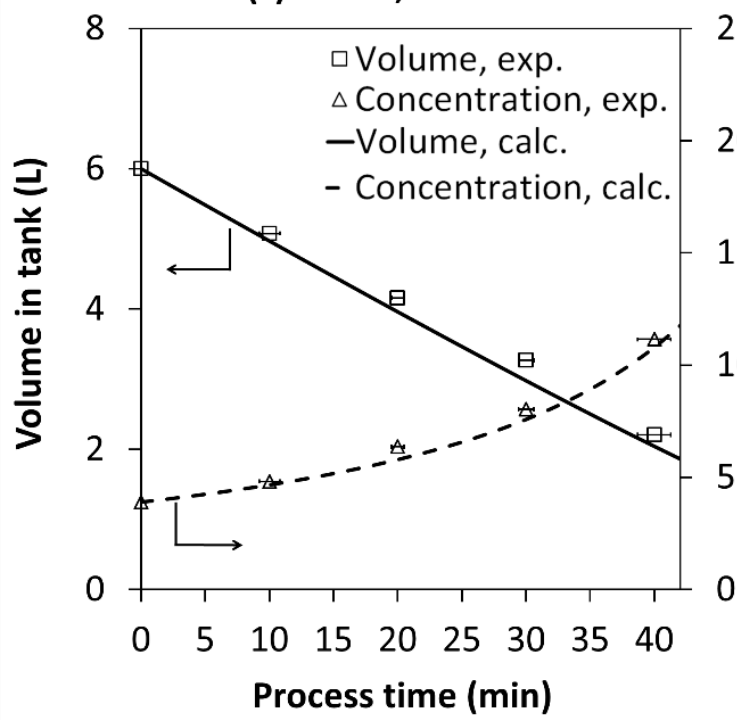

(b) 10 bar, $240 \mathrm{~L} \mathrm{~h}^{-1}$
25

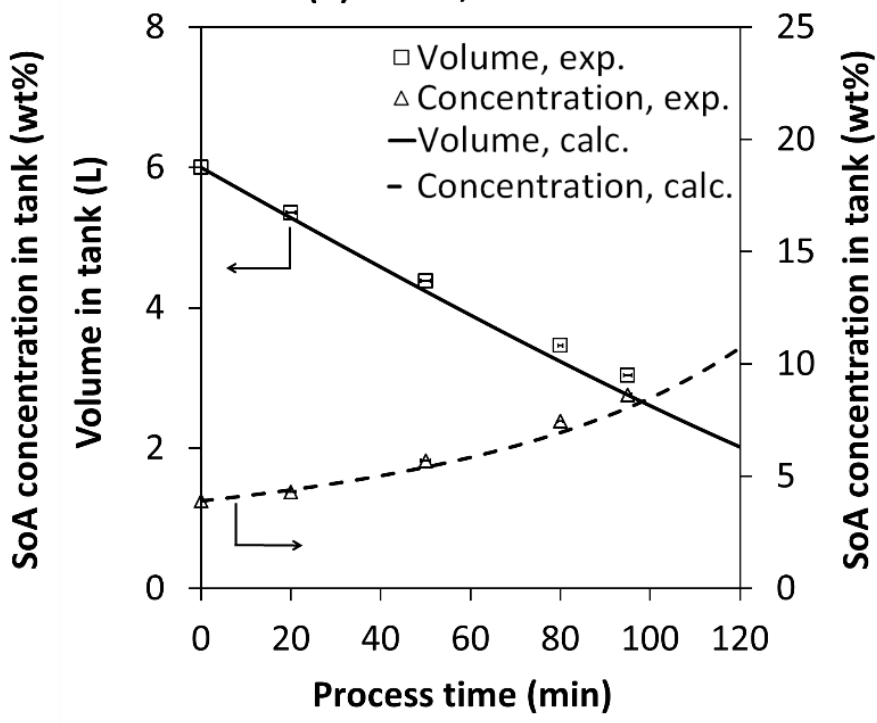

(d) 30 bar, $240 \mathrm{~L} \mathrm{~h}^{-1}$

25

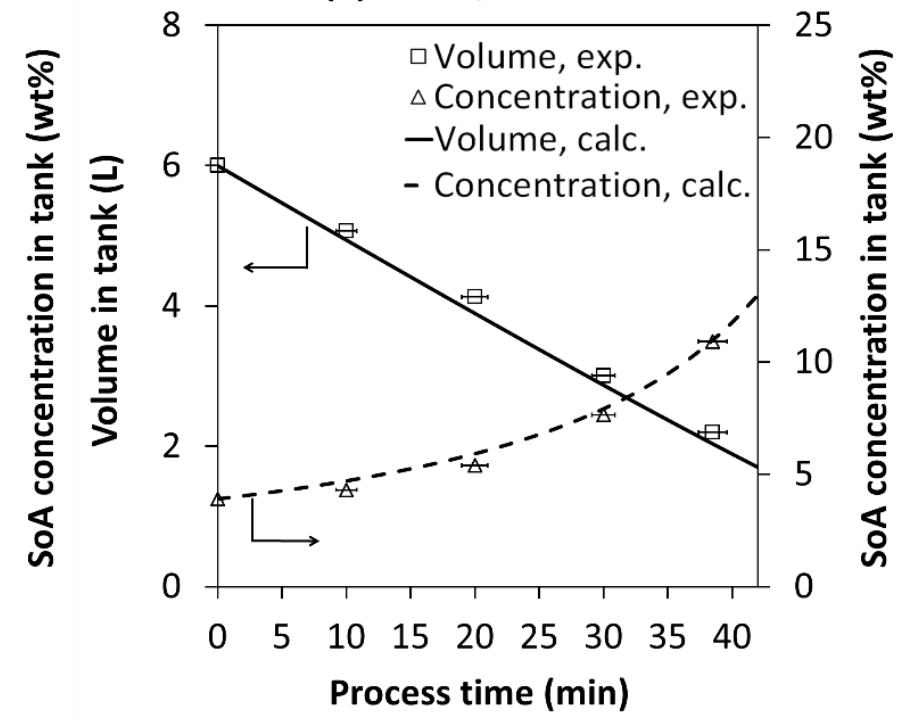

Figure 3: Experimental (exp.) and calculated (calc.) performance of the batch concentration process over time with a 1.8"x12" spiral-wound PuraMem ${ }^{\circledR}$ S600 membrane module tested at 30 ${ }^{\circ} \mathrm{C}$ with various feed pressures and retentate flowrates (Entries $1-4$ in Table 2). The error bars on the $\mathrm{x}$-axis indicate the time spent to take the samples and record the data. 
(a) 10 bar, $300 \mathrm{~L} \mathrm{~h}^{-1}$

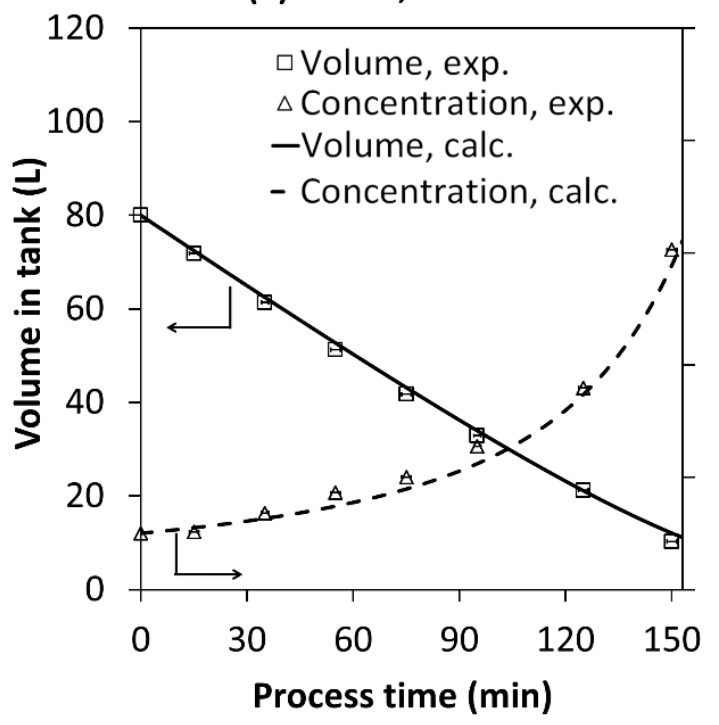

(c) $30 \mathrm{bar}, 300 \mathrm{Lh}^{-1}$

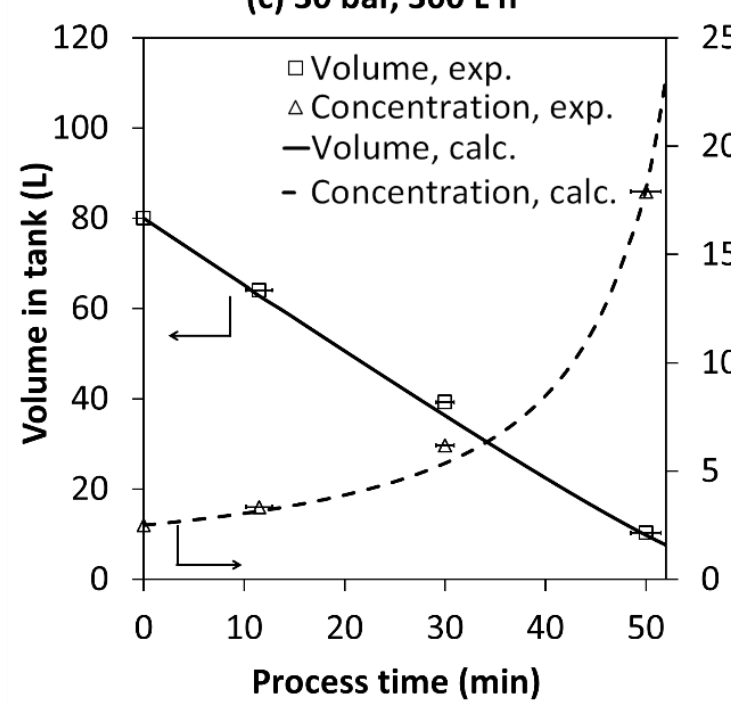

(b) $10 \mathrm{bar}, 900 \mathrm{~L} \mathrm{~h}^{-1}$
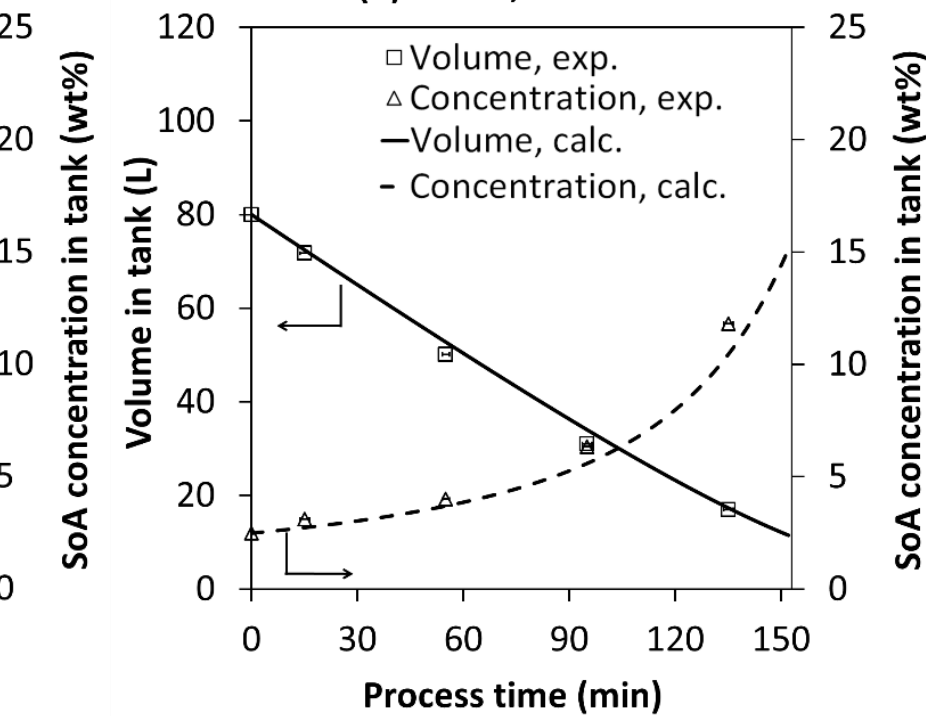

(d) 30 bar, $900 \mathrm{Lh}^{-1}$

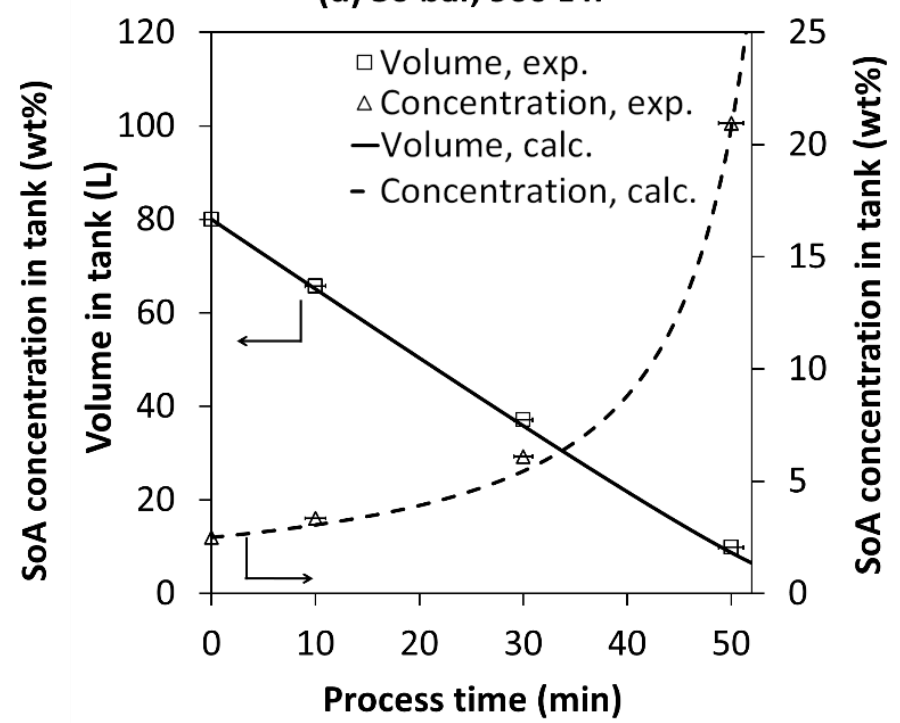

Figure 4: Experimental (exp.) and calculated (calc.) performance of the batch concentration process over time with a 2.5 "x40" spiral-wound PuraMem ${ }^{\circledR}$ S600 membrane module tested at 30 ${ }^{\circ} \mathrm{C}$ with various feed pressures and retentate flowrates (Entries $5-8$ in Table 2). The error bars on the $\mathrm{x}$-axis indicate the time spent to take the samples and record the data. 
(a) $10 \mathrm{bar}, 1000 \mathrm{~L} \mathrm{~h}^{-1}$

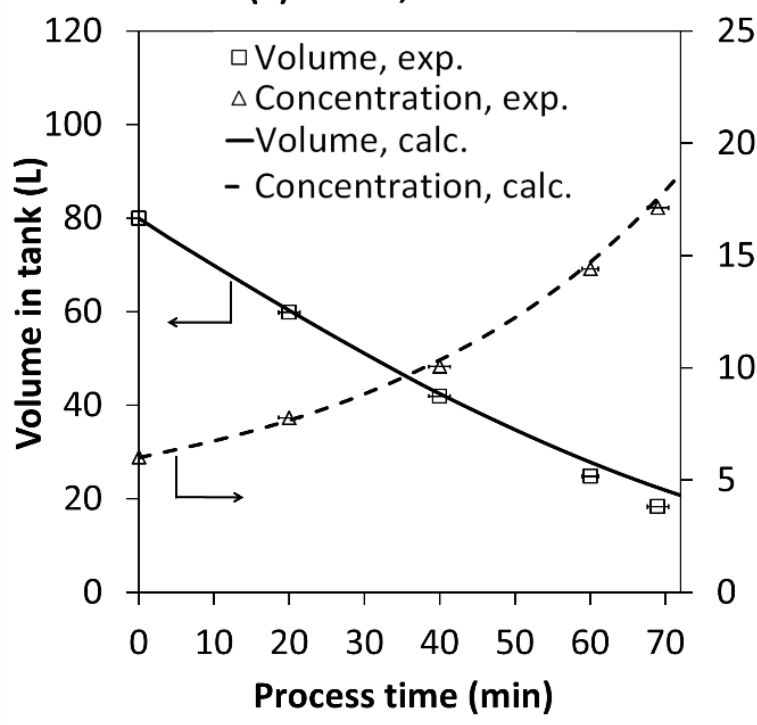

(c) 30 bar, $1000 \mathrm{~L} \mathrm{~h}^{-1}$

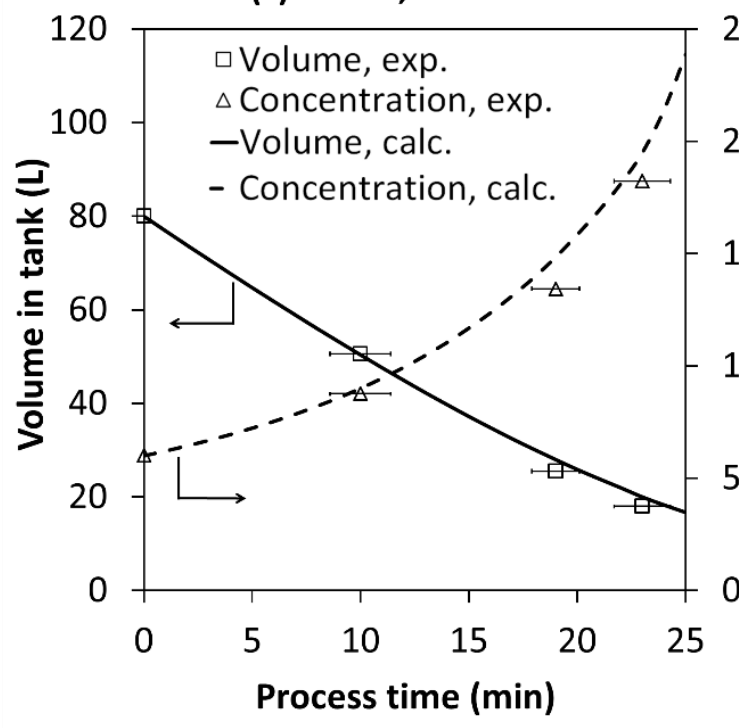

(b) $10 \mathrm{bar}, 3000 \mathrm{Lh}^{-1}$

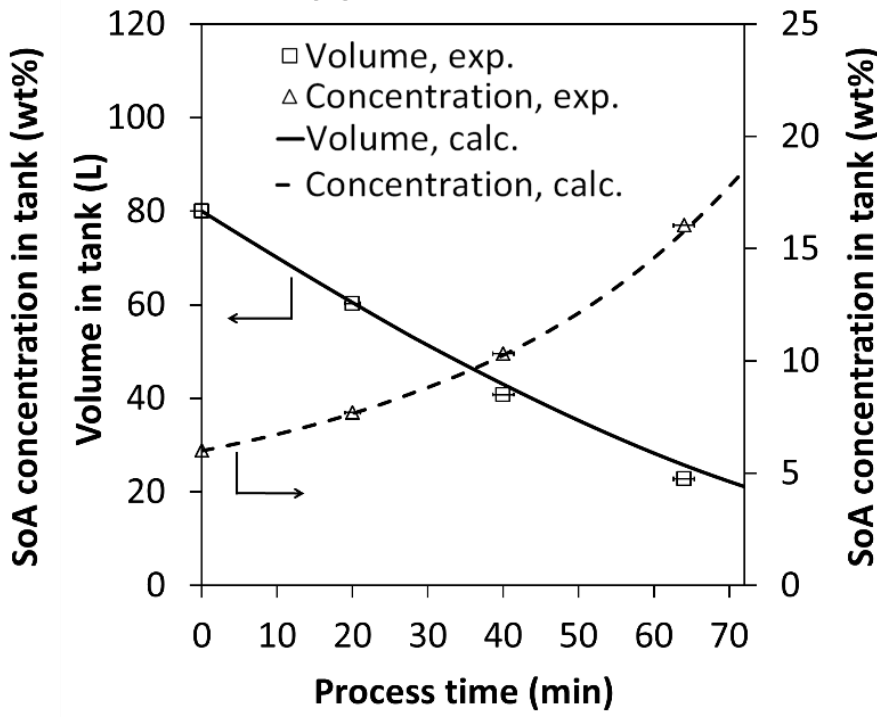

(d) $30 \mathrm{bar}, 3000 \mathrm{~L} \mathrm{~h}^{-1}$

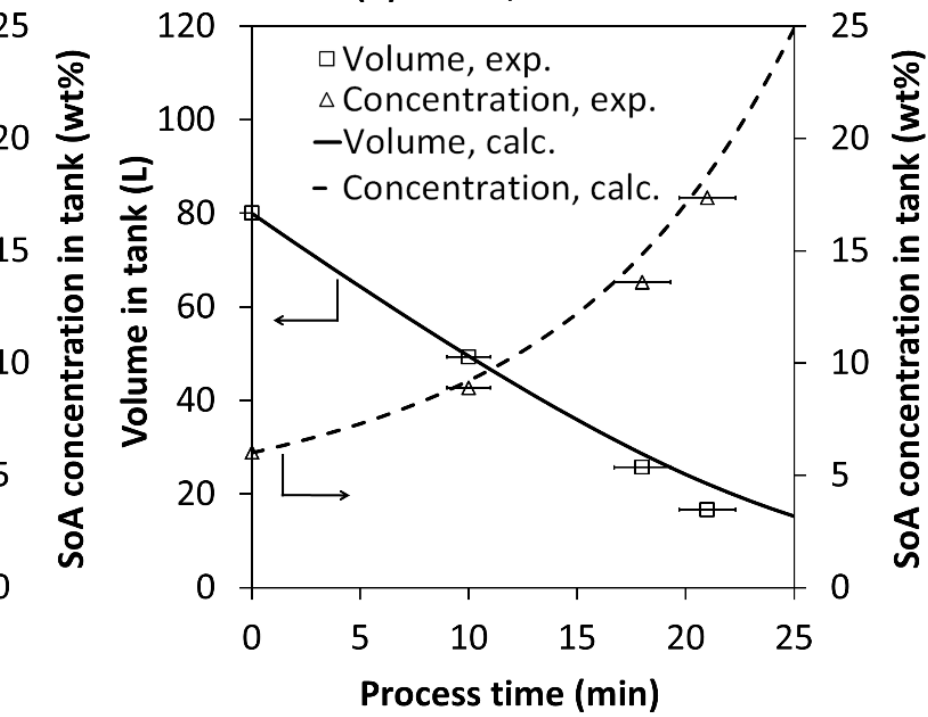

Figure 5: Experimental (exp.) and calculated (calc.) performance of the batch concentration process over time with a 4.0"x40" spiral-wound PuraMem ${ }^{\circledR}$ S600 membrane module tested at 30 ${ }^{\circ} \mathrm{C}$ with various feed pressures and retentate flowrates (Entries $9-12$ in Table 2). The error bars on the $\mathrm{x}$-axis indicate the time used to take the samples and record the data.

For all three module sizes, very good agreement was observed between the experimental and simulated module performance (see Figures $3-5$ ). This indicates that the performance of the batch concentration process with spiral-wound membrane modules can be predicted from laboratory crossflow flat sheet data when both the fluid dynamics and mass transfer characteristics and necessary geometry for spacer-filled channels in the modules are known. Moreover, the success of this approach in predicting the performance of the batch concentration 
shows the potential for using it in other OSN processes. The OSN Designer tool provides the all necessary thermodynamic and physical properties of various solute/solvent combinations.

In industrial membrane concentration processes, such as the recovery of a valuable compound in the pharmaceutical industry, or the recovery of solvents in the chemical industry, often the membrane rejection is high but not total (100\%) [Buonomenna and Bae, 2015]. In this case it is very important to control the loss of solute to permeate during the process. Besides the intrinsic membrane rejection, the fluid dynamics in the module has an effect on the loss of solute to permeate too. Figure 6 shows the percentage loss of SoA to permeate during the batch concentration processes studied in this work under various operating conditions. It is clear that the increase in the retentate flowrate effectively reduces the loss of solute to permeate. This is due to a decrease in the concentration polarisation and an increase in the solute rejection at high retentate flowrates. This effect is more obvious when the concentration of the solution is high (represented by the increasing relative difference between the performance at low and high retentate flowrates in Figure 6(a-c)). Besides, in this study increasing the feed pressure reduced the solute loss to permeate, represented by the relative difference between the performance at low and high pressures in Figure 6(a-c). It is due to the fact that the ratio of solute flow to permeate to solvent flow to permeate (solute concentration in permeate) reduced when the feed pressure increased from 10 bar to 30 bar, resulting in higher rejection, according to the simulation data. This trend was also observed in the experiments with the same membrane modules in SoA/EA solutions in steady-state operation [Shi et al., 2015] and in the rejection of glutathione using hollow fibre membranes [Sun et al., 2010]. 
(a) $1.8 " x 12 "$

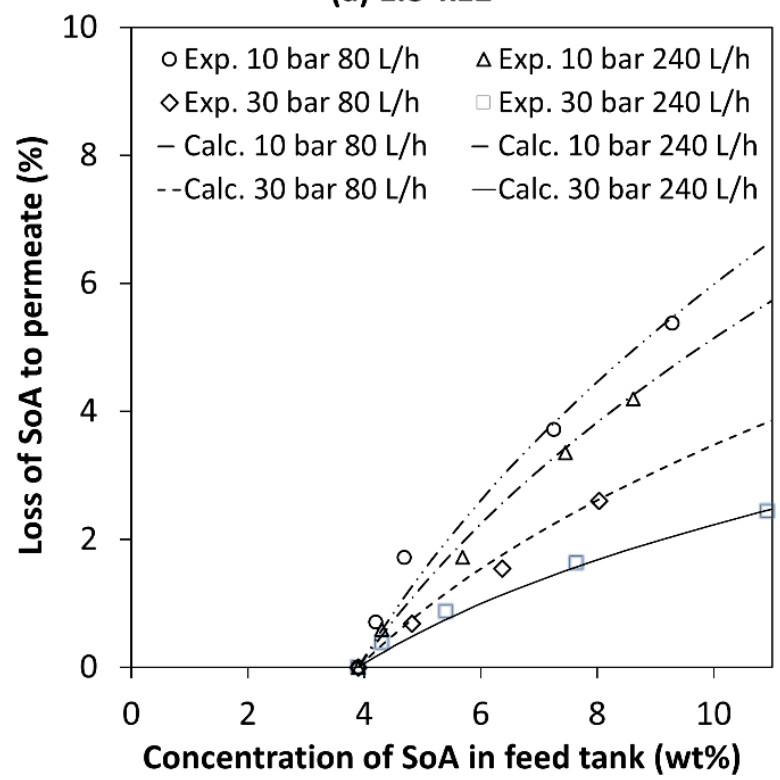

(b) 2.5 " $\times 40 "$

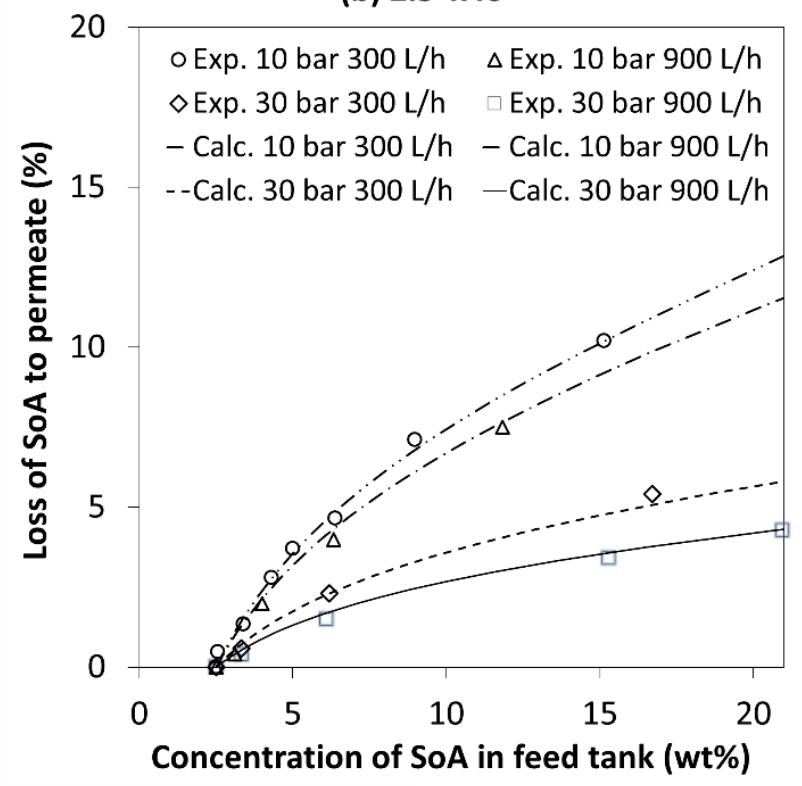

(c) $4.0 " \times 40 "$

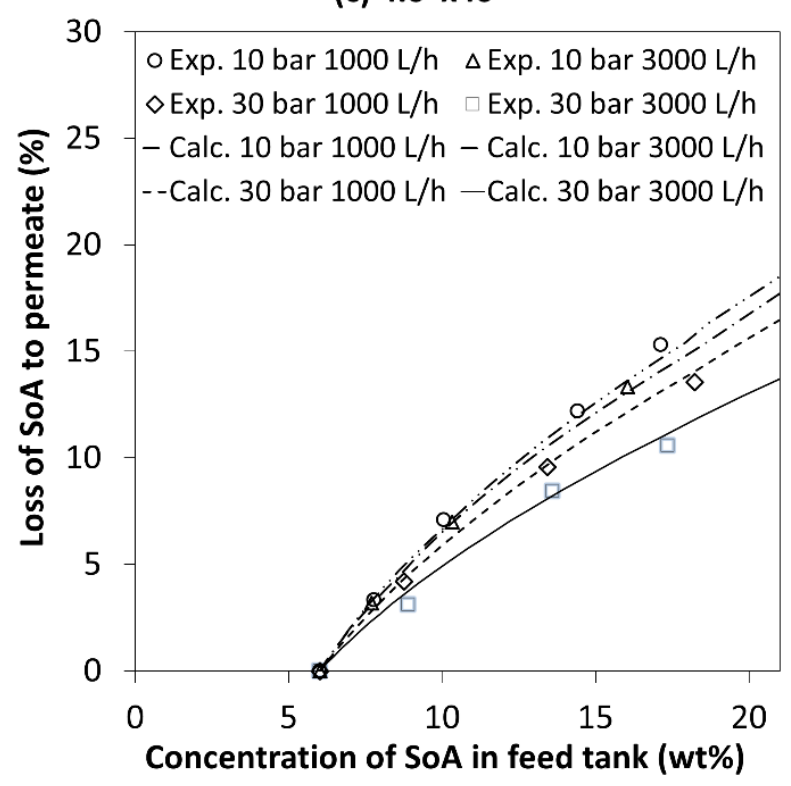

Figure 6. Experimental (exp.) and calculated (calc.) percentage loss of the solute in the batch concentration process under various retentate flowrates and feed pressures at $30^{\circ} \mathrm{C}$ with three different commercial spiral-wound membrane modules: (a) 1.8"x12" spiral-wound membrane module; (b) 2.5"x4.0" spiral-wound membrane module; (c) 4.0"x40" spiral-wound membrane module.

Although increasing the feed pressure accelerates the process and reduces the loss of solute to permeate, increasing the feed pressure can damage the membrane when the feed pressure exceeds the maximum pressure the membrane can tolerate. Moreover, the increase of the 
membrane flux causes increases of the pressure drop in the permeate channels. This strongly limits the benefit of having a higher flux from increasing the feed pressure. Similarly, the benefit of increasing the retentate flowrate on the concentration process has the drawback of requiring higher energy consumption. Besides, the increase of the retentate flowrate may cause telescoping and even damage the modules. In conclusion, during the process design, the optimal value of the feed pressure and retentate flowrate for a specific application has to be identified, in terms of process efficiency, solute recovery and energy consumption.

Figure 7 shows the importance of considering feed and permeate pressure drop in the simulation of volume reduction and solute concentration after 10 minutes of operation (see Figure 7(a)) and after 50 minutes of operation, i.e. at the end of the process (see Figure 7(b)). The simulation was carried out accounting for the friction coefficients in both feed and permeate channels (entry "Both feed and permeate pressure drop" in Figure 7), as well as by accounting for pressure drop in the permeate channel only (entry "Only permeate pressure drop" in Figure 7) or accounting for the pressure drop in the feed channel only ("Only feed pressure drop" in Figure 7). The gradients of concentration and velocity through both feed and permeate channels, the concentration polarisation and the thermodynamic non-ideality of the solution were considered in all the cases. Very good agreement between the experiments and the calculation was obtained when both feed and permeate pressure drop were taken into consideration. It can be seen that when the permeate pressure drop only is considered in the model, there is also good agreement between experimental and calculated data, although the accuracy is slightly lower. This is due to the negligible feed pressure drop in this specific case study (<0.5 bar). In industrial applications where several modules are connected in series, however, the feed pressure drop may become important. The impact of the permeate pressure drop on both volume and concentration is almost negligible at the beginning of the process (see Figure 7(a)) and much more significant at the end of the process (see Figure 7 (b)). This suggests that the pressure drop through the permeate channel of the module must be known, in order to accurately predict the performance of the batch concentration process using spiral-wound membrane modules. 
(a) Process time $\mathrm{t}=10 \mathrm{~min}$

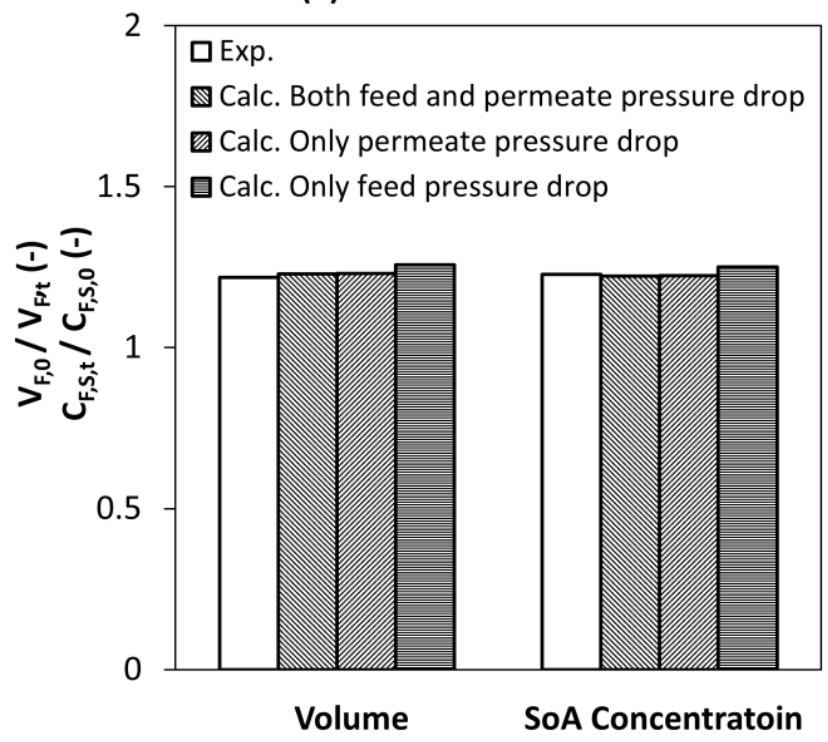

(b) Process time $\mathbf{t}=\mathbf{5 0} \mathrm{min}$

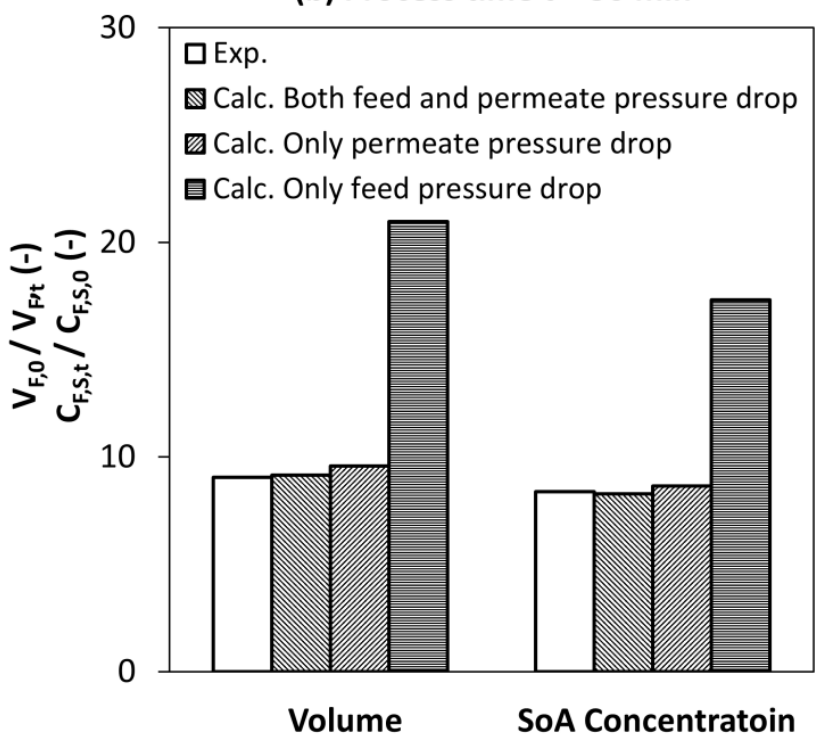

Figure 7: Experimental (exp.) and calculated (calc.) normalised volume and solute concentration during the batch concentration process of sucrose octaacetate in ethyl acetate with the 2.5 "x40" spiral-wound membrane module and effect of feed and permeate pressure drop at different process times: (a) 10 minutes and (b) 50 minutes. The process was run at $30{ }^{\circ} \mathrm{C}$ and 30 bar with a retentate flowrate of $900 \mathrm{~L} \mathrm{~h}^{-1}$. Volume and solute concentration were normalised with respect to the initial solution volume $\left(V_{F, 0}\right)$ and solute concentration $\left(C_{F, S, 0}\right)$.

The effects of concentration polarisation on the performance of the batch concentration process with the 2.5 "x40" spiral-wound membrane module are shown in Figure 8 . To simulate the absence of concentration polarisation, the simulation was carried out assuming a very large Sherwood number (of $10^{36}$ ). At the beginning of the process (11.5 minute, see Figure $8(a)$ ), the difference between the simulation with and without accounting for the concentration polarisation was negligible and good agreement with the experimental data was observed. This is due to the relatively low concentration of the feed solution at the beginning of the process $(<10 \mathrm{wt} \%)$. On the other hand, the effect of concentration polarisation becomes important when the feed concentration is high. In fact, the calculation considering concentration polarisation showed good agreement with the experimental data while the one neglecting the concentration polarisation showed a deviation of $35 \%$. 
(a) Process time $\mathrm{t}=\mathbf{1 1 . 5} \mathrm{min}$

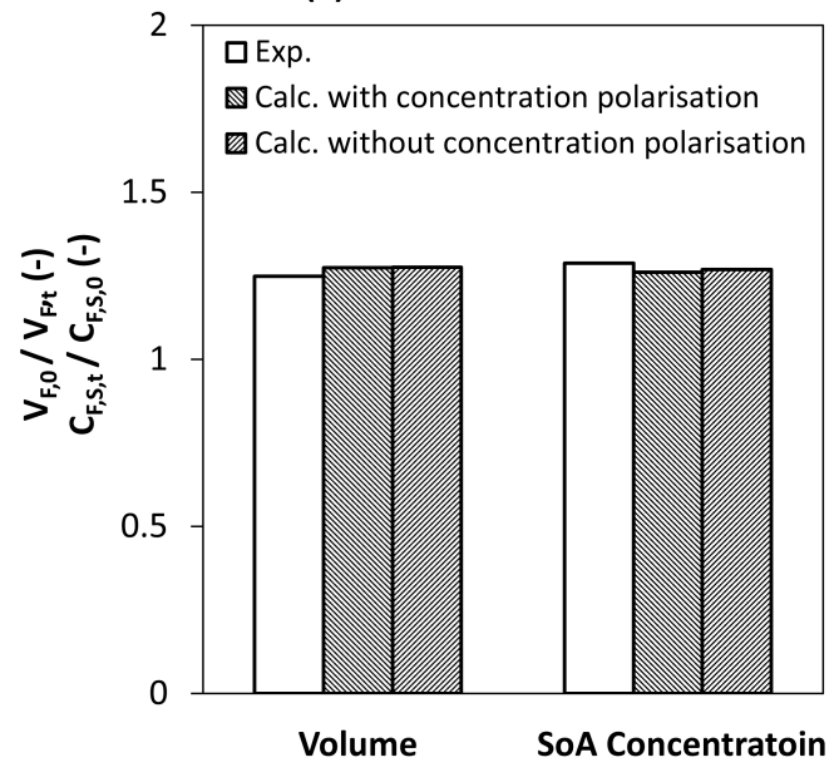

(b) Process time $\mathbf{t}=\mathbf{5 0} \mathrm{min}$

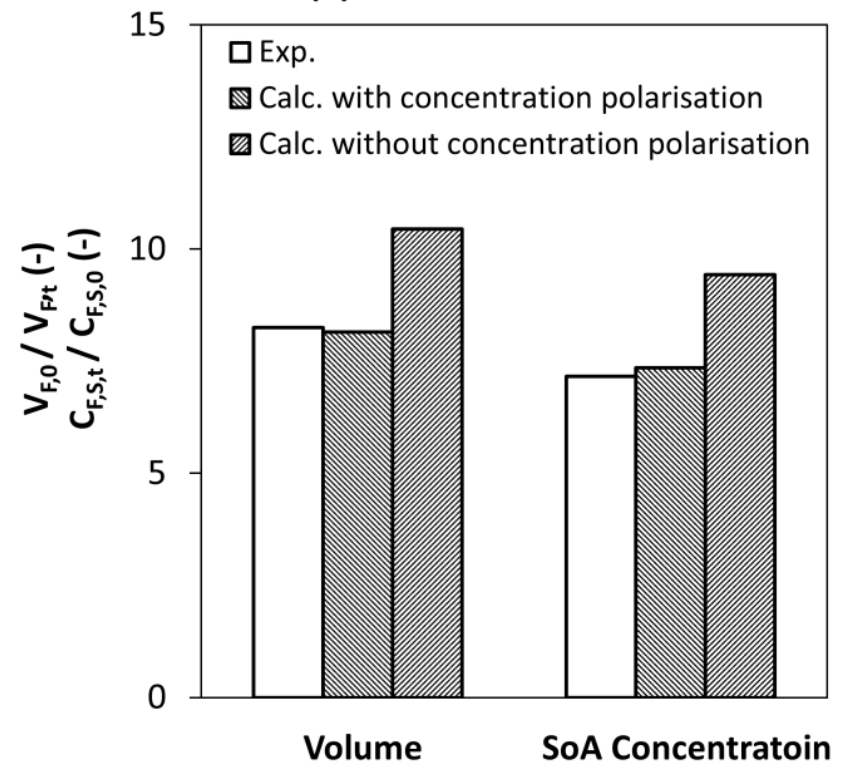

Figure 8: Experimental (exp.) and calculated (calc.) normalised volume and solute concentration during the batch concentration process of sucrose octaacetate in ethyl acetate with the 2.5 " $x 40$ " spiral-wound membrane module and effect of concentration polarisation at different process times: (a) 11.5 minutes and (b) 50 minutes. The process was run at $30{ }^{\circ} \mathrm{C}$ and 30 bar with retentate flowrate of $300 \mathrm{~L} \mathrm{~h}^{-1}$. Volume and solute concentration were normalised with respect to the initial solution volume $\left(\mathrm{V}_{\mathrm{F}, 0}\right)$ and solute concentration $\left(\mathrm{C}_{\mathrm{F}, \mathrm{S}, 0}\right)$.

A third factor, which has impact on the process performance, is the thermodynamic non-ideality of the solution. Therefore, a simulation of batch concentration process with the 2.5 "x40" spiralwound membrane module was performed in order to assess the importance of this factor. The results are shown in Figure 9. The simulations were carried out accounting for the activity coefficient of both solute and solvent (entry "Gamma = UNIFAC-DMD") or assuming that the activity coefficient of both solute and solvent was 1 (entry "Gamma $=1$ "). The difference between the simulations with and without accounting for the thermodynamic non-ideality of the solutions at the beginning of the process (11.5 minute) was negligible, and good agreement with the experimental data was observed. This can be explained by the relatively low deviation from the ideal behaviour at initial concentration ( $<10 \mathrm{wt} \%)$. On the other hand, the effect of solution nonideality became important at the end of the process (50 minutes, see Figure 9(b)) when the feed concentration was high (about $18 \mathrm{wt} \%$ ). The simulation considering ideal solution underestimated the performance of about $13 \%$. These results indicate that thermodynamic non-ideality has 
significant impact on the process performance when highly concentrated solutions are involved in the process in agreement with previous studies [Peshev and Livingston, 2013; Peeva et al., 2004; Stamatialis et al., 2006].

(a) Process time $\mathbf{t}=\mathbf{1 1 . 5} \mathbf{m i n}$

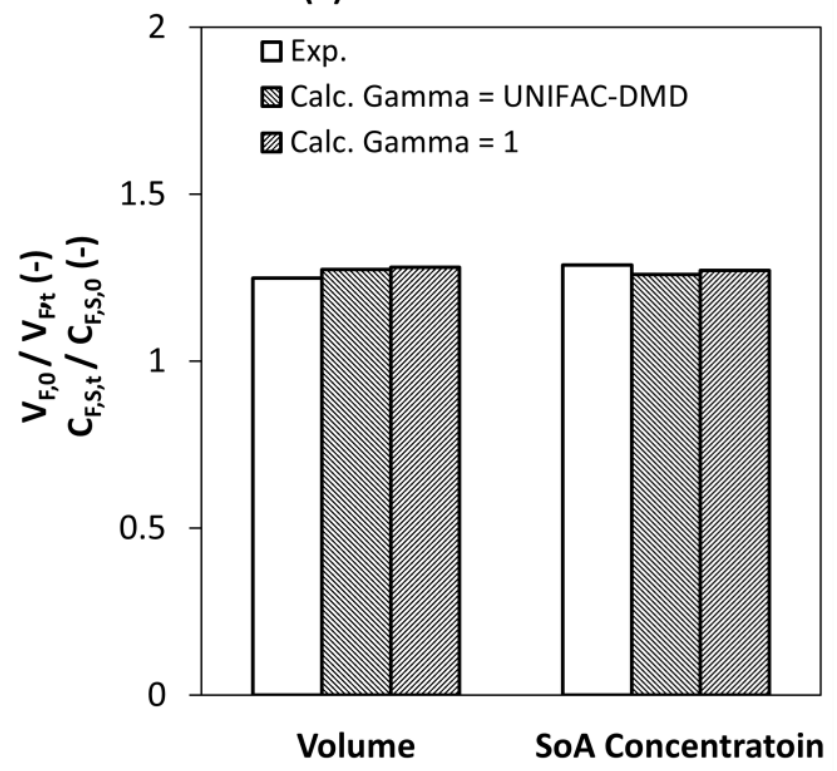

(b) Process time $\mathrm{t}=\mathbf{5 0} \mathrm{min}$

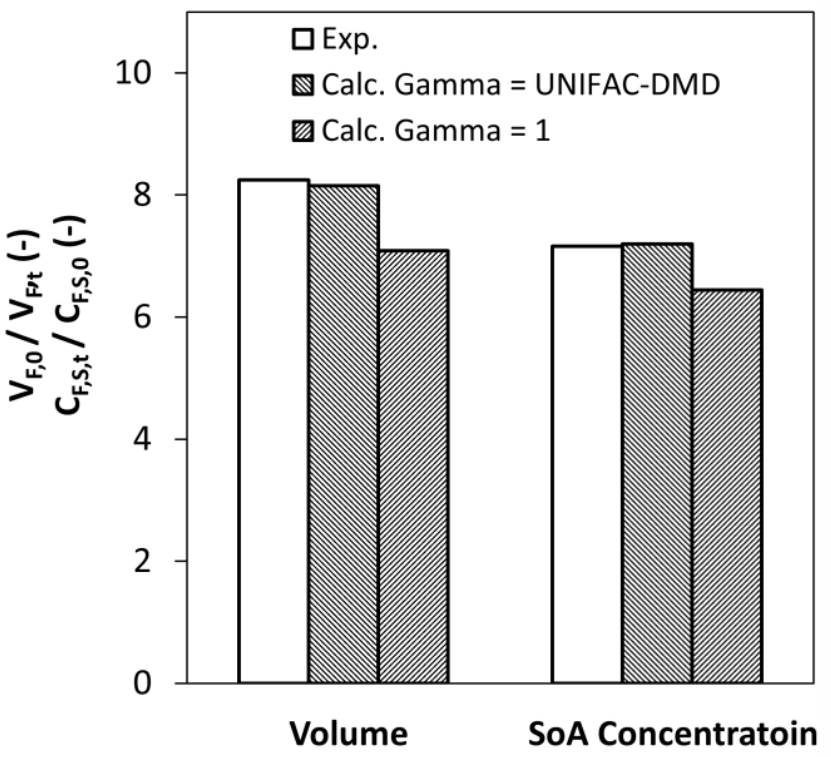

Figure 9: Experimental (exp.) and calculated (calc.) normalised volume and solute concentration during the batch concentration process of sucrose octaacetate in ethyl acetate with the 2.5 " $x 40 "$ spiral-wound membrane module and effect of thermodynamic non-ideality at different process times: (a) 11.5 minutes and (b) 50 minutes. The process was run at $30^{\circ} \mathrm{C}$ and 30 bar with retentate flowrate of $300 \mathrm{~L} \mathrm{~h}^{-1}$. Volume and solute concentration were normalised with respect to the initial solution volume $\left(\mathrm{V}_{\mathrm{F}, 0}\right)$ and solute concentration $\left(\mathrm{C}_{\mathrm{F}, \mathrm{S}, 0}\right)$.

\section{Conclusions}

Experimental data on batch concentration process performance with three commercial spiralwound membrane modules of different sizes up to 4.0 "x40" in sucrose octaacetate / ethyl acetate solutions under various pressures and retentate flowrates were reported. It was observed that increasing the feed pressure can accelerate the batch concentration process and effectively reduce the solute loss to permeate due to the increase in both the permeate flux and rejection. Similarly, it was observed that increasing the retentate flowrate makes the concentration process slightly faster and decreases the solute loss to permeate. However, in an industrial application, 
increasing the feed pressure may damage the membrane when the feed pressure exceeds the maximum pressure the membranes can tolerate, and also brings more safety concerns. The increase of the retentate flowrate may cause telescoping and even damage the modules, and requires higher energy consumption. Therefore, during the process design, the optimal value of the feed pressure and retentate flowrate for a specific application has to be identified, in terms of process efficiency, solute recovery and energy consumption.

A mathematical model to describe the membrane batch concentration process was developed, based on combination of the classical solution diffusion membrane transport model and the film theory, to account for the mass transfer effects. The model was implemented using the "OSN Designer" software tool. The parameters of the membrane transport model were obtained from flat sheet test data and the parameters necessary to describe the pressure drops and the mass transfer characteristics of the modules were obtained from a regression procedure on a limited number of experimental data on the 1.8 "X12" module under steady state conditions. The pressure drop through the permeate channel of the module was shown to affect significantly the performance of the batch concentration process, therefore it must be known, in order to accurately predict the performance of the batch concentration process using spiral-wound membrane modules. On the other hand, the effect of the feed pressure drop on the batch concentration performance was found to be negligible in this case study since the feed pressure drops were negligible (< 0.5 bar). However, the feed channel pressure drop may become important in industrial applications where several modules are connected in series. Besides, it was also found that the mass transfer resistance and thermodynamic non-ideality of the solution have to be taken into account, in order to accurately simulate the membrane batch concentration performance.

Very good agreement was found between the batch concentration performance data under various operating conditions and the simulation obtained by the multi-scale modelling procedure, indicating that the performance of a batch concentration process with a spiral-wound membrane module can be predicted from laboratory crossflow flat sheet test data when both the fluid dynamics and mass transfer characteristics in the module and the necessary channel geometry are known. Moreover, the success of this approach in predicting the performance of the batch 
concentration process shows the potential for using this approach in other OSN processes, and the OSN Designer tool provides the possibility of obtaining the thermodynamic and physical properties of various solute/solvent combinations.

The process model presented in this paper does not consider the effect of fouling on the process performance, since fouling was not observed from the module autopsy after the experiments in this study, neither in a previous study featuring the same mock solutions and modules [Shi et al., 2015]. However, for a particular application where fouling is expected to affect the overall process performance, it is possible to modify the transport model in MATLAB code to include the occurrence of fouling (a suitable model to describe fouling should be identified for the specific application of the interest). Finally, this process model has the potential to do an optimisation since it can be used to simulate the process performance under various conditions and it has access to the build-in model analysis functions which can be applied to carry out process optimization and economic evaluation in Aspen Plus using the "OSN Designer".

\section{Nomenclature}

List of symbols

$\begin{array}{ll}A & \text { effective membrane area }\left(\mathrm{m}^{2}\right) \\ a & \text { coefficient in friction coefficient correlation (dimensionless) } \\ b & \text { exponent of Reynolds number in friction coefficient correlation (dimensionless) } \\ C_{F, S, 0} & \text { initial concentration of solute in feed }\left(\mathrm{mol} \mathrm{m}^{-3}\right) \\ C_{F, S, t} & \text { concentration of solute in feed at process time } t\left(\mathrm{~mol} \mathrm{~m}^{-3}\right) \\ C_{P, S, t} & \text { concentration of solute in permeate collection tank at process time } t\left(\mathrm{~mol} \mathrm{~m}^{-3}\right) \\ d_{h} & \text { hydraulic diameter }(\mathrm{m}) \\ f & \text { friction coefficient (dimensionless) } \\ J_{i} & \text { molar permeate flux of species } i\left(\mathrm{~mol} \mathrm{~m}^{-2} \mathrm{~s}^{-1}\right) \\ J_{V, t} & \text { module flux at process time } t\left(\mathrm{~m}^{3} \mathrm{~m}^{-2} \mathrm{~s}^{-1}\right) \\ k & \text { mass transfer coefficient }\left(\mathrm{m} \mathrm{s}^{-1}\right) \\ L & \text { length of channel }(\mathrm{m}) \\ P & \text { pressure (Pa) }\end{array}$




$\begin{array}{ll}P_{m, i} & \text { permeability coefficient of species } i\left(\mathrm{~mol} \mathrm{~m} \mathrm{~m}^{-2}\right) \\ \Delta P & \text { Pressure drop (Pa) } \\ R & \text { ideal gas constant }\left(\mathrm{Pa} \mathrm{m}^{3} \mathrm{~mol}^{-1} \mathrm{~K}^{-1}\right) \\ R e & \text { Reynolds number (dimensionless) } \\ R e j_{S, t} & \text { observed rejection of solute at process time } t(\%) \\ S c & \text { Schmidt number (dimensionless) } \\ S h & \text { Sherwood number (dimensionless) } \\ T & \text { temperature (K) } \\ V_{F, t} & \left.\text { solution volume in feed tank at process time } t \text { (m }{ }^{3}\right) \\ V_{P, t} & \text { solution volume in permeate collection tank at process time } t\left(\mathrm{~m}^{3}\right) \\ x_{i} & \text { molar fraction of species } i \text { in solution (dimensionless) }\end{array}$

Greek symbols

$\alpha \quad$ coefficient in Sherwood number correlation (dimensionless)

$\beta \quad$ exponent of Reynolds number in Sherwood number correlation (dimensionless)

$\lambda \quad$ exponent of Schmidt number in Sherwood number correlation (dimensionless)

$\rho \quad$ density $\left(\mathrm{kg} \mathrm{m}^{-3}\right)$

$v_{i} \quad$ molar volume of species $i\left(\mathrm{~m}^{3} \mathrm{~mol}^{-1}\right)$

$\gamma_{i} \quad$ activity coefficient of species $i$ (dimensionless)

Subscripts

$F \quad$ feed solution or feed channel

FM feed side membrane-liquid interface

$P \quad$ permeate solution or permeate channel

$t \quad$ process time $t$

Abbreviations

EA ethyl acetate

OSN organic solvent nanofiltration

SoA sucrose octaacetate 


\section{Acknowledgments}

The research leading to these results had received funding from the European Community's Seventh Framework Programme under grant agreement MemTide 238291 FP7-PEOPLE-ITN-2008 and from EPSRC under the Project EP/J014974/1 entitled Molecular Builders: Constructing Nanoporous Materials.

\section{Reference}

Buonomenna, M.G., Bae, J., 2015. Organic solvent nanofiltration in pharmaceutical industry. Separation and Purification Reviews 44, 157 - 182.

Cao, X., Wu, X.Y., Wu, T., Jin, K., Hur, B.K., 2001. Concentration of 6-Aminopenicillanic Acid from Penicillin Bioconversion Solution and Its Mother Liquor by Nanofiltration membrane. Biotechnol. Bioprocess Eng. 6, $200-204$.

Fimbres-Weihs, G.A., Wiley, D.E., 2007. Numerical study of mass transfer in three-dimensional spacer-filled narrow channels with steady flow. J. Membr. Sci. 306, 228.

Koutsou, C.P., Yiantsios, S.G., Karabelas, A.J., 2009. A numerical and experimental study of mass transfer in spacer-filled channels: Effects of spacer geometrical characteristics and Schmidt number. J. Membr. Sci. 326, 234.

Li, F., Meindersma, G.W., de Haan, A.B., Reith, T., 2002. Optimization of non-woven spacers by CFD and validation by experiments. Desalination 146, 209.

Marchetti, P., Butté, A., Livingston, A.G., 2013. Quality by Design for peptide nanofiltration: Fundamental understanding and process selection. Chem. Eng. Sci. 101, $200-212$.

Marchetti, P., Livingston, A.G., 2015. Predictive membrane transport models for Organic Solvent Nanofiltration: How complex do we need to be? J. Membr. Sci. 476, $530-553$.

Othman, R., Mohammad, A.W., Ismail, M., Salimon, J., 2010. Application of polymeric solvent resistant nanofiltration membranes for biodiesel production. J. Membr. Sci. 348, 287 - 297. 
Peeva, L.G., Gibbins, E., Luthra, S.S., White, L.S., Stateva, R.P., Livingston, A.G., 2004. Effect of concentration polarisation and osmotic pressure on flux in organic solvent nanofiltration. J. Membr. Sci. 236, 121.

Peshev, D., Livingston, A.G., 2013. OSN Designer, a tool for predicting organic solvent nanofiltration technology performance using Aspen One, MATLAB and CAPE OPEN. Chem. Eng. Sci. $104,975-987$.

Peshev, D., Peeva, L.G., Baptista, I.I.R., Boam, A.T., 2011. Application of organic solvent nanofiltration for concentration of antioxidant extracts of rosemary (Rosmarinus officiallis L.). Chem. Eng. Res. and Des. 89, 318.

Schock, G., Miquel, A., 1987. Mass transfer and pressure loss in spiral wound modules. Desalination 64, 339.

Schwinge, J., Wiley, D.E., Fane, A.G., Guenther, R., 2000. Characterization of a zigzag spacer for ultrafiltration. J. Membr. Sci. 172, 19.

Sereewatthanawut, I., Lim, F.W., Bhole, Y.S., Ormerod, D., Horvath, A., Boam, A.T., Livingston, A.G., 2010. Demonstration of molecular purification in polar aprotic solvents by organic solvent nanofiltration. Org. Process Res. Dev. 14, $600-611$.

Sheth, J.P., Qin, Y., Sirkar, K.K., Baltzis, B.C., 2003. Nanofiltration-based diafiltration process for solvent exchange in pharmaceutical manufacturing. J. Membr. Sci. 211, $251-261$.

Shi, B., Marchetti, P., Peshev, D., Zhang, S., Livingston, A.G., 2015. Performance of Spiral-Wound Membrane Modules in Organic Solvent Nanofiltration - Fluid Dynamics and Mass Transfer Characteristics. J. Membr. Sci. 494, 8 - 24.

Stamatialis, D.F., Stafie, N., Buadu, K., Hempenius, M., Wessling, M., 2006. Observations on the permeation performance of solvent resistant nanofiltration membranes. J. Membr. Sci. 279, $424-$ 433.

Sun, S.P., Chung, T.S., Lu, K.J., Chan, S.Y., 2014. Enhancement of flux and solvent stability of

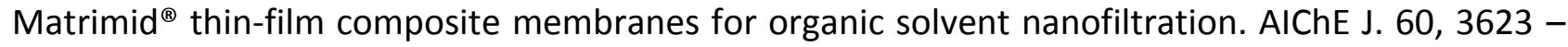
3633. 
Sun, S.P., Wang, K.Y., Rajarathnam, D., Hatton, T.A., Chung, T.S., 2010. Polyamide-imide nanofiltration hollow fibre membranes with elongation-induced nano-pore evolution. AIChE J. 56, $1481-1494$.

Tsibranska, I.H., Tylkowski, B., 2013. Concentration of ethanolic extracts from Sideritis ssp. L. by nanofiltration: Comparison of dead-end and cross-flow modes. Food Bioprod. Process 91, 169 174.

Tsui, E.M., Cheryan, M., 2007. Membrane processing of xanthophylls in ethanol extracts of corn. J. Food Eng. 83, $590-595$.

Van der Gryp, P., Barnard, A., Cronje, J.P., de Vlieger, D., Marx, S., Vosloo, H.C.M., 2010. Separation of different metathesis Grubbs-type catalyst using organic solvent nanofiltration. J. Membr. Sci. 353, $70-77$.

Vanneste, J., De Ron, S., Vandecruys, S., Soare, S.A., Darvishmanesh, S., Van der Bruggen, B., 2011. Techno-economic evaluation of membrane cascades relative to simulated moving bed chromatography for the purification of mono- and oligosaccharides. Sep. Purif. Technol. 80, 600.

Vanneste, J., Ormerod, D., Theys, G., Gool, D.V., Camp, B.V., Darvishmanesh, S., der Bruggen, B.V., 2013. Towards high resolution membrane based pharmaceutical separations. J. Chem. Technol. Biotechnol. 88, 98.

Werhan, H., Farshori, A., Rudolf von Rohr, P., 2012. Separation of lignin oxidant products by organic solvent nanofiltration. J. Membr. Sci. 423-424, 404-412.

White, L.S., 2006. Development of large-scale applications in organic solvent nanofiltration and pervaporation for chemical and refining processes. J. Membr. Sci. 286, $26-35$. 